\title{
Maternal smoking during pregnancy, environmental tobacco smoke exposure and childhood lung function
}

Frank D Gilliland, Kiros Berhane, Rob McConnell, W James Gauderman, Hita Vora, Edward B Rappaport, Edward Avol, John M Peters

\begin{abstract}
Background-Exposure to environmental tobacco smoke (ETS) during childhood and in utero exposure to maternal smoking are associated with adverse effects on lung growth and development.

Methods-A study was undertaken of the associations between maternal smoking during pregnancy, exposure to ETS, and pulmonary function in 3357 school children residing in 12 Southern California communities. Current and past exposure to household ETS and exposure to maternal smoking in utero were assessed by a self-administered questionnaire completed by parents of 4 th, 7 th, and 10th grade students in 1993. Standard linear regression techniques were used to estimate the effects of in utero and ETS exposure on lung function, adjusting for age, sex, race, Hispanic ethnicity, height, weight, asthma, personal smoking, and selected household characteristics.
\end{abstract}

Results-In utero exposure to maternal smoking was associated with reduced peak expiratory flow rate (PEFR) $(-3.0 \%, 95 \%$ CI -4.4 to -1.4$)$, mean mid expiratory flow (MMEF) $(-4.6 \%, 95 \%$ CI -7.0 to -2.3$)$, and forced expiratory flow $\left(\mathrm{FEF}_{75}\right)(-6.2 \%, 95 \%$ CI -9.1 to -3.1), but not forced expiratory volume in one second $\left(\mathrm{FEV}_{1}\right)$. Adjusting for household ETS exposure did not substantially change these estimates. The reductions in flows associated with in utero exposure did not significantly vary with sex, race, grade, income, parental education, or personal smoking. Exposure to two or more current household smokers was associated with reduced MMEF $(-4.1 \%, 95 \%$ CI -7.6 to -0.4$)$ and $\mathrm{FEF}_{75}$ $(-4.4 \%, 95 \%$ CI -9.0 to 0.4$)$. Current or past maternal smoking was associated with reductions in PEFR and MMEF; however, after adjustment for in utero exposure, deficits in $\mathrm{MMEF}$ and $\mathrm{FEF}_{75}$ associated with all measurements of ETS were substantially reduced and were not statistically significant.

Conclusions-In utero exposure to maternal smoking is independently associated with decreased lung function in children of school age, especially for small airway flows.

(Thorax 2000;55:271-276)

Keywords: maternal smoking; pregnancy; environmental tobacco smoke; lung function; children
Environmental tobacco smoke (ETS) is an important worldwide public health issue..$^{1-3}$ The effect of exposure to household ETS on children has been one focus of concern. Children have been identified as a sensitive group for ETS because exposure during childhood can be high and because the period of growth and development may be an especially vulnerable one for its effects. In the USA an estimated 15 million children, accounting for more than $25 \%$ of the population in this age group, are currently exposed to household ETS and are at risk for adverse health effects from this exposure. ${ }^{4}$

The effects of ETS on children's respiratory health have been extensively investigated. ${ }^{1-3}$ Previous studies in children have produced substantial evidence that ETS adversely affects lung growth and development. In most, but not all, studies of lung function in children ETS is associated with reduced levels of pulmonary function tests. Although not as extensively investigated, recent reports suggest that in utero exposure is associated with deficits in lung function at birth that may persist into young adulthood..$^{5-12}$ Because in utero exposure to maternal smoking and ETS exposure during childhood are highly correlated, both exposures need to be considered in assessing the adverse effects of tobacco smoke on pulmonary function tests. The limited information available suggests that in utero exposure may be associated with a persistent deficit and that current exposure may produce an additional reduction in lung function. ${ }^{5613}$

The Children's Health Study at the University of Southern California offers an opportunity to investigate further the effects of in utero exposure to cigarette smoking and childhood ETS exposure on lung function. To investigate the effect of in utero exposure on lung function we examined cross sectional data collected in 1993 to determine whether in utero and ETS exposure were associated with decreased lung function among 3357 school children residing in 12 Southern California communities.

\section{Methods}

The elements of the Southern California Children's Health Study have been described previously. ${ }^{14}{ }^{15}$ A total of 3681 children (approximately $50 \%$ fourth graders (mean age 10 years), $25 \%$ seventh graders (mean age 13 years), and $25 \%$ tenth graders (mean age 16 years)) were recruited from public school 
classrooms in 12 communities that were selected based on historical measurements of air quality, demographic similarities, and a cooperative school district. In early 1993 the parents or guardians of each participating student provided written informed consent and completed a written questionnaire which provided demographic information, characterised history of respiratory illness and its associated risk factors, exposure information, and household characteristics.

Current and past exposure to household ETS and exposure to maternal smoking in utero were characterised using the responses from the questionnaire completed by parents or guardians. Household smoking was defined as daily smoking inside the house by anyone living in the home. Information was collected about the current and past household smoking status of each participant's mother, father, other adult household members, and regular household visitors. Past or current parental smoking was classified into categories of mother, father, or other smokers that were not mutually exclusive categories. The current number of household smokers $(1,2,3,4,5$, and 6 or more) and the current number of cigarettes smoked inside the house per day (none, 1-9, 10-29, 30-59, 60-79, and 80 or more) were recorded. Based on the distribution of responses, the number of smokers were categorised in the analyses as 0,1 , and 2 or more household smokers and the number of cigarettes per day as $0,1-9$, and 10 or more cigarettes per day. In utero exposure to maternal smoking (yes or no) was assigned by responses to the question "Did your child's biological mother smoke while she was pregnant with your child? (include time when she was pregnant but did not yet know she was)". To investigate the independent and joint effects of in utero and environmental exposure to tobacco smoke we categorised exposure into the following mutually exclusive categories: none, any current or past household ETS only, in utero exposure to maternal smoking only, or both in utero and household ETS exposure. Personal smoking by participants was defined as a history of ever smoking more than 100 cigarettes ascertained by a private interview during spirometric tests. To account for variation in exposure arising from differences in house size, we constructed additional exposure estimates by dividing the number of household smokers and the number of cigarettes smoked per day in the house by the number of rooms in the house.

Most lung function testing (91.5\%) was completed during the morning hours of the spring months in order to avoid daily and annual peak pollution. Students in each community were tested during two or three visits to each school and no more than half of the subjects in each community was tested during one visit. Maximum forced expiratory flow-volume manoeuvres were recorded using rolling seal spirometers (Spiroflow, PK Morgan Ltd, Gillingham, UK). The spirometers were calibrated just before, during, and just after each testing session using flow-volume syringes
(Jones Medical Instrument Co, Oak Brook, Illinois, USA) and variables for individual spirometers and technicians were included in the statistical models. Testing and data management procedures have been reported previously. ${ }^{14}$ Each subject was asked to perform three satisfactory manoeuvres. A satisfactory manoeuvre was defined as the forced vital capacity (FVC) agreeing within 5\%, the forced expiratory volume in one second $\left(\mathrm{FEV}_{1}\right)$ agreeing within $5 \%$, an extrapolated volume for $\mathrm{FEV}_{1}$ less than $100 \mathrm{ml}$ or $5 \%$ of FVC, an expiration in the final two seconds of less than approximately $50 \mathrm{ml}(45 \mathrm{ml}$ times the standard BTPS correction factor), and forced expiratory time exceeding three seconds. These criteria are based on the American Thoracic Society's recommendations modified for children. ${ }^{16}$ No more than seven manoeuvres were attempted. At the time of testing, students had height and weight measured and had a private interview about personal smoking habits, recent respiratory illness history, and whether they had performed vigorous exercise within half an hour of the test. Of the 3681 children participating in the study, lung function data were obtained from $3361(93 \%)$. Both questionnaire data and lung function measurements were available for 3357 children.

The distributions of pulmonary function tests were examined univariately using descriptive statistics and stratified analyses. Standard linear regression techniques were used to assess the effects of in utero and ETS effects on pulmonary function levels adjusting for age, sex, race, Hispanic ethnicity, height, weight, personal smoking, and selected characteristics. In univariate analyses we found that pulmonary function tests were linearly related to height within grade groups after logarithmic transformation of both variables. To model the relationship between $\mathrm{FVC}, \mathrm{FEV}_{1}$, mean mid expiratory flow (MMEF), peak expiratory flow rate (PEFR), forced expiratory flow $\left(\mathrm{FEF}_{75}\right)$ and height, log transformed pulmonary function tests were regressed on log transformed height. To account for differential patterns of lung growth with respect to age, sex, and race, we included interaction terms of sex with grade, and sex and grade with age, race, height, and weight in all models. As described previously, a large number of potential confounding and/or effect modifying variables describing household characteristics, medical history, and demographics were also considered in the analysis. ${ }^{14}$ Stepwise multiple regression was used to determine which demographic medical history variables, indoor exposures, and housing characteristics were significantly correlated with each pulmonary function test after adjustment for community, grade in school, sex, technician, and spirometer. Covariates that were significant at the $\mathrm{p}<0.15$ level were included in the models. Using this selection process, body mass index and possession of a gas stove were included in models of all pulmonary function tests except $\mathrm{FEF}_{75}$, ever having asthma in all models except those for FVC, and having a cat in models for $\mathrm{FEV}_{1}$ and FVC. In addition, current asthma 
symptoms and hayfever were in models for MMEF and $\mathrm{FEF}_{75}$, and having household pests or pets or recent exercise were included in the model for PEFR. Personal smoking by participants was defined as smoking more than 100 cigarettes. Although the number of ever smokers was small, the effect of personal smoking was considered by excluding ever smokers from analyses and by modelling personal smoking as a potential confounder or effect modifier.

We also considered age, sex, race/ethnicity, parent education, family income, insurance status, history of asthma, family history of asthma (maternal, paternal, or both parents), and personal smoking as potential confounders or modifiers of the relationship between tobacco smoke exposure and lung function using interaction terms and stratified models. The above linear regression models were applied to all subjects in the data set using an appropriate interaction term, and to subsets defined by potential modifying variables.

\section{Results}

Questionnaires and lung function tests were administered to 3357 students in the 12 communities (table 1). Most participants were white, non-Hispanic, and had health insurance. Overall, $19.3 \%$ of students were exposed to maternal smoking in utero and $41.5 \%$ were ever exposed to household ETS (table 2). Tobacco smoke exposure varied markedly between racial and ethnic groups. The proportion of participants exposed to household ETS was highest in 10th graders, Native
Americans, and non-Hispanics. Exposure to tobacco smoke was more frequent among students from homes with lower income and parental education.

In utero exposure to maternal smoking was associated with reduced lung function (table 3). The largest percentage deficits were for measures related to small airway flows, MMEF $(-4.6 \%, 95 \%$ CI -7.0 to -2.3$)$ and $\mathrm{FEF}_{75}$ $(-6.2 \%, 95 \%$ CI -9.1 to -3.1$)$. Adjusting for any current or past household ETS exposure did not substantially change these estimates. We found no evidence that other measurements of ETS exposure-including any past exposure alone, any current exposure alone, postnatal maternal or paternal smoking, the number of current household smokers, the current number of cigarettes smoked in the household per day, or measurements adjusted for the size of the house-affected the magnitude of the deficits associated with in utero exposure (data not shown).

Deficits in lung function were also observed for children with ETS exposure; however, the percentage change was much smaller and was substantially explained by in utero exposure to maternal smoking (tables 4 and 5). Exposure to two or more current household smokers was associated with reduced MMEF $(-4.1 \%, 95 \%$ CI -7.6 to -0.4$)$ and $\mathrm{FEF}_{75}(-4.4 \%, 95 \%$ CI -9.1 to -0.4). MMEF and PEFR were lower in children exposed to maternal smoking $(-2.7 \%$ and $-1.7 \%$, respectively). However, after adjustment for in utero exposure, the flow deficits associated with current ETS exposure or with current and past maternal smoking were

Table 1 Characteristics and exposure to tobacco smoke of participants in the Children's Health Study, 1993

\begin{tabular}{|c|c|c|c|c|}
\hline & $\begin{array}{l}\text { Total no. (\%) } \\
\text { of children }\end{array}$ & $\begin{array}{l}\text { Any ETS exposure } \\
\text { No. exposed (\% of } \\
\text { subgroup exposed) }\end{array}$ & $\begin{array}{l}\text { Current ETS exposure } \\
\text { No. exposed (\% of } \\
\text { subgroup exposed) }\end{array}$ & $\begin{array}{l}\text { In utero exposure } \\
\text { No. exposed (\% of } \\
\text { subgroup exposed) }\end{array}$ \\
\hline \multicolumn{5}{|l|}{ Grade } \\
\hline 4 & $1660(50 \%)$ & $603(45 \%)$ & $351(47 \%)$ & $303(49 \%)$ \\
\hline 7 & $863(25 \%)$ & $352(27 \%)$ & $190(25 \%)$ & $154(25 \%)$ \\
\hline 10 & $834(24 \%)$ & $370(28 \%)$ & $208(28 \%)$ & $163(26 \%)$ \\
\hline \multicolumn{5}{|l|}{ Sex } \\
\hline Girls & $1728(52 \%)$ & $705(53 \%)$ & $395(53 \%)$ & $318(51 \%)$ \\
\hline \multicolumn{5}{|l|}{ Race } \\
\hline White & $2148(67 \%)$ & $899(69 \%)$ & $518(71 \%)$ & $473(78 \%)$ \\
\hline Black & $158(5 \%)$ & $72(6 \%)$ & $48(7 \%)$ & $32(5 \%)$ \\
\hline Asian & $172(5 \%)$ & $50(4 \%)$ & $31(4 \%)$ & $4(1 \%)$ \\
\hline Native American & $42(1 \%)$ & $26(2 \%)$ & $11(2 \%)$ & $11(2 \%)$ \\
\hline Other & $470(15 \%)$ & $143(11 \%)$ & $66(9 \%)$ & $38(6 \%)$ \\
\hline Mixed & $230(7 \%)$ & $105(8 \%)$ & $59(8 \%)$ & $50(8 \%)$ \\
\hline \multicolumn{5}{|l|}{ Hispanic ethnicity } \\
\hline Yes & $840(26 \%)$ & $295(23 \%)$ & $154(21 \%)$ & $105(17 \%)$ \\
\hline \multicolumn{5}{|l|}{ Health insurance } \\
\hline Yes & $2720(84 \%)$ & $1073(83 \%)$ & $592(8 \%)$ & $517(85 \%)$ \\
\hline Asthma (ever diagnosed) & $471(14 \%)$ & $194(15 \%)$ & $120(16 \%)$ & $109(18 \%)$ \\
\hline \multicolumn{5}{|l|}{ Hayfever } \\
\hline Yes & $541(18 \%)$ & $218(18 \%)$ & $127(18 \%)$ & $111(20 \%)$ \\
\hline \multicolumn{5}{|l|}{ Child smoking } \\
\hline Yes & $98(3 \%)$ & $62(5 \%)$ & $48(6 \%)$ & $30(5 \%)$ \\
\hline \multicolumn{5}{|l|}{ Household income (\$) } \\
\hline$<7500$ & $156(6 \%)$ & $86(8 \%)$ & $56(9 \%)$ & $49(9 \%)$ \\
\hline $7500-14999$ & $276(10 \%)$ & $157(14 \%)$ & $111(18 \%)$ & $78(15 \%)$ \\
\hline $15000-29999$ & $430(16 \%)$ & $214(18 \%)$ & $134(22 \%)$ & $101(19 \%)$ \\
\hline $30000-49000$ & $756(28 \%)$ & $307(27 \%)$ & $154(24 \%)$ & $141(26 \%)$ \\
\hline $50000-99000$ & $933(33 \%)$ & $313(27 \%)$ & $147(24 \%)$ & $150(27 \%)$ \\
\hline $100000+$ & $184(7 \%)$ & $50(5 \%)$ & $21(3 \%)$ & $19(4 \%)$ \\
\hline \multicolumn{5}{|l|}{ Parental education } \\
\hline$<12$ th grade & $476(15 \%)$ & $217(17 \%)$ & $143(19 \%)$ & $99(16 \%)$ \\
\hline$=12$ th grade & $672(21 \%)$ & $310(24 \%)$ & $183(25 \%)$ & $160(26 \%)$ \\
\hline Some college & $1343(41 \%)$ & $595(45 \%)$ & $329(45 \%)$ & $289(48 \%)$ \\
\hline 4 year college & $342(11 \%)$ & $96(7 \%)$ & $51(7 \%)$ & $30(5 \%)$ \\
\hline Postgraduate & $390(12 \%)$ & $89(7 \%)$ & $32(4 \%)$ & $30(5 \%)$ \\
\hline
\end{tabular}

ETS $=$ environmental tobacco smoke.

*Self-reported physician diagnosed asthma. 
Table 2 Distribution of in utero and ETS exposure among participants in the Children's Health Study, 1993 $(n=3357)$

\begin{tabular}{lc}
\hline & No. $(\%)$ \\
\hline Exposure & \\
In utero & $620(19)$ \\
Any past or current ETS household exposure & $1325(42)$ \\
Current household smokers & \\
Mother & $435(13)$ \\
Father & $405(12)$ \\
Other & $174(5)$ \\
Number of current household smokers & \\
0 & $2509(77)$ \\
1 & $482(15)$ \\
$2+$ & $266(8)$ \\
Number of cigarettes/day & \\
0 & $2349(75)$ \\
$1-9$ & $366(12)$ \\
$10+$ & $415(13)$ \\
Past ETS household exposure & \\
Mother & $576(18)$ \\
Father & $645(20)$ \\
Other & $174(5)$ \\
In utero and any past or current ETS household exposure \\
No in utero and no ETS & $1756(56)$ \\
Only ETS & $759(24)$ \\
In utero and no ETS & $82(3)$ \\
In utero and ETS & $527(17)$ \\
\hline ETS environg
\end{tabular}

ETS = environmental tobacco smoke.

Table 3 Effects of in utero exposure to maternal smoking on lung function level, percentage change and $95 \%$ confidence intervals ( $95 \%$ CI), Children's Health Study, $1993(n=3357)$

\begin{tabular}{lll}
\hline PFT & $\begin{array}{l}\text { Unadjusted for ETS } \\
\text { \% change }(95 \% \text { CI) }\end{array}$ & $\begin{array}{l}\text { Adjusted for ETS } \\
\text { \% change }(95 \% \text { CI })\end{array}$ \\
\hline FEV $_{1}$ & $-1.0(-2.1$ to 0.1$)$ & $-0.9(-2.1$ to 0.2$)$ \\
FVC & $+0.6(-0.4$ to 1.6$)$ & $+0.7(-0.4$ to 1.8$)$ \\
PEFR & $-3.0(-4.4$ to -1.4$)$ & $-2.2(-3.9$ to -0.6$)$ \\
MMEF & $-4.6(-7.0$ to -2.3$)$ & $-4.3(-6.9$ to -1.8$)$ \\
FEF $_{75}$ & $-6.2(-9.1$ to -3.1$)$ & $-6.2(-9.4$ to -2.8$)$ \\
\hline
\end{tabular}

${ }^{\star}$ Any past or current environmental tobacco smoke (ETS). $\star \star$ Models are adjusted for community, grade, spirometer, technician, log (height), age, sex, race, weight and weight ${ }^{2}$, two way interactions of sex and grade with age, race, log (height), weight and weight ${ }^{2}$ and selected medical and household characteristics. $\mathrm{PFT}=$ pulmonary function test $\mathrm{FEV}_{1}=$ forced expiratory volume in one second; FVC = forced vital capacity; PEFR = peak expiratory flow rate; $\mathrm{MMEF}=$ mean mid expiratory flow; FEF $=$ forced expiratory flow.

substantially reduced and were generally no longer statistically significant, except for PEFR for children with one smoker in the house. Use of the other measurements of ETS exposure described above resulted in the same pattern of findings (data not shown). In contrast, FVC was lower for those exposed to paternal smoking and adjustment for in utero exposure, which was not associated with FVC, had little effect.

Consideration of the joint effects of household ETS and in utero exposure using mutually exclusive categories suggests that in utero exposure has an independent effect on small airway flows (table 6). Information from our questionnaire allowed the separation of children into four exposure categories: no in utero or lifetime exposure to household ETS $(56.2 \%)$; any lifetime exposure to household ETS only $(24.3 \%)$; in utero exposure only $(2.6 \%)$; and both any lifetime household exposure to ETS and in utero exposure (16.9\%). Children with a history of in utero exposure only and those with in utero exposure plus postnatal ETS exposure showed deficits in $\mathrm{MMEF}$ and $\mathrm{FEF}_{75}$ of 3-8\%. Exposure solely to household ETS was not associated with significant deficits in flows. The pattern of deficits was the same when only maternal smoking or current ETS exposure measures were considered. We found little evidence that the magnitude of the deficits associated with in utero exposure varied by sex, race, age, income, parental education, insurance status, ETS exposure, or personal smoking.

\section{Discussion}

The results of this study show that in utero exposure to maternal smoking is associated with a reduction in small airway flow rates, after accounting for any lifetime household

Table 4 Number of current household smokers and lung function level, percentage change, and $95 \%$ confidence intervals (95\% CI), Children's Health Study, 1993 $(n=3357)$

\begin{tabular}{cll}
\hline $\begin{array}{l}\text { No. of household } \\
\text { smokers }\end{array}$ & $\begin{array}{l}\text { Unadjusted for in utero } \\
\text { exposure } \\
\text { \% change (95\% CI) }\end{array}$ & $\begin{array}{l}\text { Adjusted for in utero } \\
\text { exposure } \\
\text { \% change (95\% CI) }\end{array}$ \\
\hline FEV $_{1}$ & - & - \\
0 & $-0.6(-1.7$ to 0.6$)$ & $-0.3(-1.5$ to 1.0$)$ \\
1 & $-0.1(-1.8$ to 1.5$)$ & $0.4(-1.4$ to 2.2$)$ \\
$2+$ & - & - \\
FVC & $-0.1(-1.2$ to 1.0$)$ & $-0.2(-1.4$ to 0.9$)$ \\
0 & $1.0(-0.5$ to 2.6$)$ & $0.7(-0.9$ to 2.4$)$ \\
1 & - & - \\
$2+$ & $-2.7(-4.3$ to -1.0$)$ & $-2.0(-3.7$ to -0.2$)$ \\
PEFR & $-2.1(-4.4$ to 0.3$)$ & $-0.9(-3.4$ to 1.7$)$ \\
0 & & - \\
1 & - & $-0.9(-3.6$ to 1.9$)$ \\
$2+$ & $-2.1(-4.7$ to 0.5$)$ & $-2.0(-5.8$ to 1.9$)$ \\
$M_{M E F}$ & $-4.1(-7.6$ to -0.4$)$ & \\
0 & - & $-0.02(-3.6$ to 3.8$)$ \\
1 & $-0.2(-5.2$ to 1.8$)$ & $-1.4(-6.4$ to 3.8$)$ \\
$2+$ & $-4.4(-9.1$ to -0.4$)$ & \\
\hline FEF & &
\end{tabular}

Models are adjusted for community, grade, spirometer, technician, $\log$ (height), age, sex, race, weight and weight ${ }^{2}$, two way interactions of sex and grade with age, race, log (height), weight and weight ${ }^{2}$, and selected medical and household characteristics.

For definitions see table 3.

Table 5 Current or past household smoking by adults and lung function level, percentage change and 95\% confidence intervals (95\% CI), Children's Health Study, 1993 $(n=3357)$

\begin{tabular}{|c|c|c|}
\hline & $\begin{array}{l}\text { Unadjusted for in utero } \\
\text { exposure } \\
\% \text { change ( } 95 \% \text { CI) }\end{array}$ & $\begin{array}{l}\text { Adjusted for in utero } \\
\text { exposure } \\
\% \text { change }(95 \% \text { CI })\end{array}$ \\
\hline \multicolumn{3}{|l|}{$\mathrm{FEV}_{1}$} \\
\hline Mother & $-0.2(-1.3$ to 0.9$)$ & $0.2(-1.1$ to 1.6$)$ \\
\hline Father & $-0.8(-1.9$ to 0.2$)$ & $-0.8(-1.8$ to 0.2$)$ \\
\hline Other & $0.3(-1.0$ to 1.6$)$ & $0.4(-0.9$ to 1.6$)$ \\
\hline \multicolumn{3}{|l|}{ FVC } \\
\hline Mother & $0.6(-0.5$ to 1.6$)$ & $-0.004(-1.2$ to 1.3$)$ \\
\hline Father & $-1.1(-2.1$ to -0.1$)$ & $-1.1(-2.1$ to -0.2$)$ \\
\hline Other & $0.2(-0.9$ to 1.4$)$ & $0.2(-1.0$ to 1.4$)$ \\
\hline \multicolumn{3}{|l|}{ PEFR } \\
\hline Mother & $-1.7(-3.2$ to -0.1$)$ & $-0.6(-2.5$ to 1.4$)$ \\
\hline Father & $-1.4(-2.9$ to 0.1$)$ & $-1.3(-2.8$ to 0.2$)$ \\
\hline Other & $-0.2(-2.1$ to 1.6$)$ & $-0.1(-1.9$ to 1.7$)$ \\
\hline \multicolumn{3}{|l|}{ MMEF } \\
\hline Mother & $-2.7(-5.1$ to -0.2$)$ & $-0.1(-3.0$ to 3.0$)$ \\
\hline Father & $-0.1(-2.5$ to 2.3$)$ & $0.1(-2.3$ to 2.5$)$ \\
\hline Other & $1.7(-1.1$ to 4.6$)$ & $1.9(-1.0$ to 4.8$)$ \\
\hline \multicolumn{3}{|l|}{$\mathrm{FEF}_{75}$} \\
\hline Mother & $-2.7(-5.9$ to 0.6$)$ & $1.3(-2.7$ to 5.4$)$ \\
\hline Father & $-0.3(-3.1$ to 3.1$)$ & $0.3(-2.8$ to 3.5$)$ \\
\hline Other & $1.7(-2.0$ to 5.6$)$ & $2.0(-1.7$ to 5.9$)$ \\
\hline
\end{tabular}

Models are adjusted for community, grade, spirometer, technician, $\log$ (height), age, sex, race, weight and weight ${ }^{2}$, two way interactions of sex and grade with age, race, $\log$ (height), weight and weight ${ }^{2}$, and selected medical and household characteristics.

For definitions see table 3. 
Table 6 Foint effects of environmental tobacco smoke (ETS) and in utero exposure to maternal smoking on lung function level, percentage change and $95 \%$ confidence intervals (95\% CI), Children's Health Study, 1993 $(n=3357)$

\begin{tabular}{ll}
\hline & \% Change (95\% CI) \\
\hline FEV $_{1}$ & \\
None & $-0.1(-1.1$ to 1.0$)$ \\
ETS only & $-0.1(-2.8$ to 2.6$)$ \\
In utero only & $-1.1(-3.9$ to 2.0$)$ \\
In utero + ETS & - \\
FVC & $-0.5(-1.4$ to 0.5$)$ \\
None & $2.1(-0.4$ to 4.6$)$ \\
ETS only & $-1.4(-4.1$ to 1.4$)$ \\
In utero only & \\
In utero + ETS & - \\
PEFR & $-0.3(-1.8$ to 1.2$)$ \\
None & $1.7(-2.2$ to 5.7$)$ \\
ETS only & $-3.6(-5.3$ to -1.2$)$ \\
In utero only & \\
In utero + ETS & - \\
MMEF & $0.2(-2.1$ to 2.6$)$ \\
None & $-3.6(-9.3$ to 2.5$)$ \\
ETS only & $-4.6(-7.2$ to 2.1$)$ \\
In utero only & \\
In utero + ETS & - \\
FEF & \\
None & $0.7(-2.3$ to 3.8$)$ \\
ETS only & $-7.6(-14.8$ to 0.2$)$ \\
In utero only & $-5.6(-8.8$ to -2.2$)$ \\
In utero + ETS & \\
\hline &
\end{tabular}

For definitions see table 3.

ETS exposure. Although ETS exposure was also associated with lower small airway flows, the deficits were substantially reduced when adjusted for in utero exposure. Using mutually exclusive exposure categories, we found further evidence that in utero exposure is independently associated with small airway flows. There was little evidence that lung volume was adversely affected by either in utero or ETS exposures.

A growing body of evidence supports the plausibility that in utero exposure can produce persistent deficits in childhood lung function. ${ }^{5} 791013$ 17-21 Recent studies of lung function in neonates and infants of mothers who smoked during pregnancy have shown that in utero exposure is associated with reduced lung function in the perinatal period. $^{79121820}$ Studies of neonates in East Boston and Perth, which excluded effects of ETS by measuring lung function near birth, reported an independent effect of in utero exposure on respiratory mechanics. ${ }^{72}$ The deficits observed at birth appear to persist into childhood and adolescence, especially in measures associated with small airway flow rates. $^{51921}$ The relative contribution of in utero exposure to maternal smoking and postnatal ETS exposure to persistent deficits in lung function is less clear. ${ }^{51}$ In an analysis of white children from 24 cites Cunningham et al reported that the effect of maternal smoking during pregnancy on lung function was larger than that for current smoking and was not reduced by adjustment for current smoking. ${ }^{6}$ The effects of current smoking were small and were not significant after adjustment for smoking during pregnancy. These investigators also noted a larger effect on measures of small airway flows than on lung volumes. Another study of inner city children by the same group of investigators also suggested an independent effect of in utero exposure to maternal smoking. ${ }^{21}$ In contrast, studies conducted in the Netherlands and New Zealand found that in utero exposure had no effect or that the effects of ETS were independent of in utero exposure. ${ }^{22}{ }^{23}$ A recent summary meta-analysis concluded that in utero exposure is likely to be associated with persistent deficits in flow indices. ${ }^{13}$ Our findings support the hypothesis that in utero exposure is independently associated with persistent deficits in lung function. Our data are also consistent with an additional contribution from ETS exposure to lung function deficits in those with in utero exposure. More studies are needed, especially results from longitudinal studies, to determine whether current exposure produces an additional decrement in lung function.

The biological mechanisms for deficits in lung function from in utero exposure to maternal smoking have not been clarified. Because the airways are fully developed at birth, it may be that the small airway deficits from in utero exposure reflect premature maturation or damage during critical periods of development that permanently alter the structure or function of the lung, such as its elastic recoil properties or immune function. ${ }^{13}$ The effects may also be mediated through the increased occurrence of perinatal respiratory problems or early infection associated with in utero exposure. ${ }^{24}$

There are some limitations that influence the interpretation of our cross sectional results. Exposure to tobacco smoke was assessed retrospectively using questionnaire responses and was not validated by objective measurements. However, exposure estimates based on questionnaire responses have been validated. ${ }^{3}{ }^{25-28} \mathrm{It}$ is possible that more misclassification of the ETS metrics than for in utero exposure could create a larger bias toward the null in the effect estimates for ETS exposure than for in utero exposure. However, because the routes and levels of exposure as well as the constituents vary qualitatively and quantitatively, the relative effects of misclassification are difficult to assess. We were unable to investigate any doseresponse relationships for in utero exposure because we lacked information on the intensity or duration of exposure. We also lacked information on a number of potential confounders such as maternal nutritional status and intake of alcohol or other potentially toxic substances during pregnancy. Our modelling strategy for pulmonary function tests may also have introduced errors into our effect estimates. ${ }^{29}{ }^{30}$ We used log-linear models to adjust for differences in pulmonary function tests arising from differences in anthropometric and demographic variables. Although pulmonary function tests are non-linearly related to height, we found that there was a linear relationship between the log transformed variables within age groups, indicating that the modelling assumptions are unlikely to be grossly violated. Furthermore, results from analyses stratified by grade, sex, or race were consistent with those from the models that included all participants. We also examined the validity of our assumptions using flexible models and found that the data were consistent with linear 
relationships. Our modelling approaches are unlikely to lead erroneously to the results presented in this study.

Our findings may have clinical and public health significance. The long term effects of in utero exposure on the growing lungs of children are of particular concern. In utero exposure is associated with lower lung function in childhood. The reductions in small airway flows may reflect more extensive underlying pathological and functional alterations in the distal airways than their magnitude suggest. If these deficits persist into adulthood, they may indicate increased risk for chronic obstructive pulmonary disease, lung cancer, and cardiovascular diseases. ${ }^{23}{ }^{31-34}$ Reducing the burden of chronic respiratory diseases associated with tobacco smoke may require the reduction of smoking among women during their childbearing years.

The statements and conclusions in this report are those of the investigators and not necessarily those of the California Air Resources Board, the Environmental Protection Agency, or the National Institute of Environmental Health Sciences. The mention of commercial products, their source, or their use in connection with material reported herein is not to be construed as either an actual or implied endorsement of such products.

This study was supported by the California Air Resources Board (Contract A033-186), the National Institute of Environmental Health Science (Grants 1PO1ESO939581-05 \#5P30ES07048-02), the US Environmental Protection Agency (Grant \# R826708-01-0), the National Heart, Lung and Blood Institute (Grant \# R01 HL/ES61768-01), and the Hastings Foundation.

1 US Environmental Protection Agency. Respiratory health effects of passive smoking: lung cancer and other disorders. effects of passive smoking:

2 US Department of Health and Human Services. The health consequences of involuntary smoking. Report of the Surgeon consequences of involuntary smoking. Report of the Surgeon ton, DC: 1986 .

3 California Environmental Protection Agency. Health effects of exposure to environmental tobacco smoke. Sacramento, CA of exposir.

4 CDC. State-specific prevalence of cigarette smoking among adults, and children's and adolescents' exposure to environmental tobacco smoke: United States, 1996 MMWR 1997;46:1038-43.

5 Cunningham JD, Dockery W, Speizer FE. Maternal smoking during pregnancy as a predictor of lung function in children. Am $\mathcal{F}$ Epidemiol 1994;139:1139-52.

6 Cunningham J, O'Connor G, Dockery DW, et al. Environmental tobacco smoke, wheezing, and asthma in children in 24 communities. Am $\mathcal{F}$ Respir Crit Care Med 1996;153. 218-24.

7 Hanrahan JP, Tager IB, Segal MR, et al. The effect of maternal smoking during pregnancy on early infant lung nal smoking during pregnancy on early in
function. Am Rev Respir Dis 1992;145:1129-35.

8 Tager IB, Segal MR, Munoz A, et al. The effect of maternal cigarette smoking on the pulmonary function of children cigarette smoking on the pulmonary function of children and adolescents. Analyses of data from

9 Tager IB, Ngo L, Hanrahan JP. Maternal smoking during pregnancy. Effects on lung function during the first 18 months of life. Am f Respir Crit Care Med 1995;152:97783.
10 Wang X, Wypij D, Gold DR, et al. A longitudinal study of the effects of parental smoking on pulmonary function in hildren 6-18 years. Am f Respir Crit Care Med 1994;149: $1420-5$

11 Lodrup K, Jaakkola J, Nafstad P, et al. In utero exposure to cigarette smoking influences lung function at birth. Eur Respir F 1997;10:1774-9.

12 Stick SM, Burton PR, Gurrin L, et al. Effects of maternal smoking during pregnancy and a family history of asthma on respiratory-function in newborn-infants. Lancet 1996; 348:1060-4.

13 Cook DG, Strachan DP, Carey IM. Parental smoking and spirometric indexes in children. Thorax 1998;53:884-93.

14 Peters JM, Avol E, Gauderman WJ, et al. A study of twelve Southern California communities with differing levels and types of air pollution. II. Effects on pulmonary function. Am 7 Respir Crit Care Med 1999;159:768-75.

15 Peters JM, Avol E, Navidi W, et al. A study of twelve Southern California communities with differing levels and types of air pollution. I. Prevalence of respiratory morbidity. Am f Respir Crit Care Med 1999;159:760-7.

16 American Thoracic Society. Standardization of spirometry: 1987 update. Statement of the American Thoracic Society. Am Rev Respir Dis 1987;136:1285-98.

17 Tager IB, Hanrahan JP, Tosteson TD, et al. Lung function, pre- and post-natal smoke exposure, and wheezing in the first year of life. Am Rev Respir Dis 1993;147:811-7.

18 Hanrahan JP, Halonen M. Antenatal interventions in childhood asthma. Eur Respir $\mathcal{F}$ 1998;27:S46-51.

19 Jedrychowski W, Flak E, Mroz E. Cigarette smoking by mothers during pregnancy and pulmonary function of their school age children. Pneumonol Alergol Polska 1997;65:60510 .

20 Lodrup KC, Jaakkola JJ, Nafstad P, et al. In utero exposure to cigarette smoking influences lung function at birth. Eur Respir F 1997;10:1774-9.

21 Cunningham J, Dockery DW, Gold DR, et al. Racial differences in the association between maternal smoking during pregnancy and lung function in children. Am 7 Respir Crit Care Med 1995;152:565-9.

22 Dijkstra L, Houthuijs D, Brunekreef B, et al. Respiratory health effects of the indoor environment in a population of Dutch children. Am Rev Respir Dis 1990;142:1172-8.

23 Sherrill DL, Martinez FD, Lebowitz MD, et al. Longitudinal effects of passive smoking on pulmonary function in New Zealand children. Am Rev Respir Dis 1992;145:113641 .

24 Dezateux C, Stocks J. Lung development and early origins of childhood respiratory illness. Br Med Bull 1997;53:40-

25 Coultas DB, Peake GT, Samet JM. Questionnaire assessment of lifetime and recent exposure to environmental tobacco smoke. Am F Epidemiol 1989;130:338-47.

26 Coultas DB, Samet JM, McCarthy JF, et al. Variability of measures of exposure to environmental tobacco smoke in the home. Am Rev Respir Dis 1990;142:602-6.

27 Oryszczyn MP, Godin J, Annesi I, et al. In utero exposure to parental smoking, cotinine measurements, and cord blood IgE. F Allergy Clin Immunol 1991;87:1169-74.

28 Ronchetti R, Bonci E, de Castro G, et al. Relationship between cotinine levels, household and personal smoking habit and season in 9-14 year old children. Eur Respir $\mathcal{F}$ 1994;7:472-6.

29 Wang X, Dockery DW, Wypij D, et al. Pulmonary function growth velocity in children 6 to 18 years of age. Am Rev Respir Dis 1993;148:1502-8.

30 Wypij D. Spline and smoothing approaches to fitting flexible models for the analysis of pulmonary function data. Am $\mathcal{F}$ Respir Crit Care Med 1996;154:S223-8.

31 Tager IB, Weiss ST, Munoz A, et al. Longitudinal study of the effects of maternal smoking on pulmonary function in children. N Engl f Med 1983;309:699-703.

32 Tager IB, Segal MR, Speizer FE, et al. The natural history of forced expiratory volumes. Effect of cigarette smoking and
respiratory symptoms. Am Rev Respir Dis 1998;138:83749 .

33 Sherrill DL, Lebowitz MD, Knudson RJ, et al. Smoking and Sherrill DL, Lebowitz MD, Knudson RJ, et al. Smoking and
symptom effects on the curves of lung function growth and decline. Am Rev Respir Dis 1991;144:17-22.

34 Burrows B, Taussig LM. "As the twig is bent, the tree inclines" (perhaps). Am Rev Respir Dis 1980;122:813-6. 